\title{
CONCEPTO Y PRAXIS DEL TERRORISMO: SU INCIDENCIA SOBRE \\ LA INESTABILIDAD POLIITICA \\ Y LA INTERRUPCIÓN DEL ESTADO \\ DE DERECHO*
}

Ignacio Undurraga Chacón

En 1984, más de 40 grupos terroristas dejaron un reguero de sangre por todo el mundo bajo la forma de bombas, secuestros y asesinatos, de acuerdo a un análisis del Centro de Estudios Estratégicos de la Universidad de Tel Aviv.

La cuota más alta de ataques terroristas durante 1984 tuvo lugar en Europa, según el estudio, citado por Gerd Langguth.

El $40,5 \%$ de todos los actos terroristas fueron cometidos en Europa; el 20,6\% en el Medio Oriente; el 15,5\% en Africa, el 14,6\% en Sudamérica, el 2,9\% en América Central y el 1,5\% en Norteamérica; Europa Oriental registró sólo un $0,2 \%$.

Este último guarismo confirma la regularidad empírica consistente en mostrar que durante el siglo 19 el terrorismo frecuentemente se desarrolló en respuesta a la represión. Mientras que hoy dia, la correlación entre los abusos y el terrorismo está lejos de ser obvia.

Asimismo, los registros estadísticos revelan que dada una severa represión, existe menor tendencia a que ocurran actos terroristas, como es el caso de Europa Oriental.

Idealmente debiera haber acuerdo si acaso el terrorismo es violencia general o una forma especial de ella; si acaso el énfasis debe ser puesto en sus propósitos políticos o en sus métodos de combate o en el carácter atípico de su estrategia; acaso sus propósitos y el carácter sistemático pueden ser aislados o, por el contrario, poner el acento en su impredecibilidad o quizás en el hecho de que muchas de sus víctimas son inocentes.

* Ponencia presentada al I Congreso Iberoamericano de Facultades de Derecho y Especialistas en Terrorismo y Estado de Derecho. Viña del Mar. Enero 1987. 
Desgraciadamente una definición tal no existe y no hay razón para esperarla en el futuro próximo. Alex Schmid en "Political Terrorism: A Research Guide" (1984), dio a conocer un listado de 109 definiciones diferentes de terrorismo acuñadas entre 1936 y 1981; desde entonces, el número ha crecido.

El propio gobierno de USA ha proporcionado 6; ejemplos de ellas son las siguientes: en 1984, una de las definiciones dadas por el Departamento de Estado, señala: "Violencia premeditada, políticamente motivada y perpetrada contra blancos u objetivos no combatientes, por grupos subnacionales o agentes clandestinos del Estado".

La definición reciente del Departamento de Defensa dice: "el uso o la amenaza de usar la fuerza o violencia ilegal contra individuos o propiedad para coaccionar o intimidar a Gobiernos o Sociedades, muchas veces con el propósito de alcanzar objetivos políticos, religiosos o ideológicos" (un Estado no puede ser acusado de practicar el terrorismo sin importar lo que el Gobierno haya hecho, dado que, el Estado, por definición, controla el monopolio del uso de la fuerza física legítima).

El ejército de USA sintetizó, en 1983, varias definiciones en una, que señala:

“El uso intencional de la violencia o amenaza de violencia para lograr objetivos de naturaleza política, religiosa o ideológica. Esto se lleva a cabo mediante la intimidación y la coacción o instigando el temor. El terrorismo involucra a un acto criminal que muchas veces es simbólico en su naturaleza (ahorcar perros por parte de Sendero Luminoso) y que se lleva a cabo para influir a un grupo más allá de las victimas". La deficiencia básica de esta definición consiste en que no se identifica al perpetrador, ya que, se confunde el "terrorismo de Estado" (Stalin) con el revolucionario o agitador.

Una fuente importante de la confusión conceptual, que tiene serios efectos sobre la ineficacia del derecho para combatir el terrorismo, consiste en que, en esencia, es una actividad criminal, como señala Abraham D. Sofaer. Así como admite que la aplicación del derecho interno en la lucha contra el crimen no lo elimina, se espera mucho menos respecto del terrorismo internacional, dado que el mundo carece de una policía y de un sistema judicial de carácter internacional.

Las Naciones Civilizadas han tratado de controlar el terrorismo internacional condenándolo, tratándolo como piratería, persiguiendo a los terroristas bajo las leyes de los Estados afectados, creando normas internacionales que definen como crímenes algunos actos donde quiera que se cometan y cooperando mediante la extradición y otras acciones consistentes en ayudar a naciones atacadas por los terroristas.

Una evaluación de esos esfuerzos conduce a una penosa conclusión: el derecho aplicable al terrorismo no es sólo defectuoso sino que es equívoco: las reglas y declaraciones diseñadas para frenar el terrorismo tienen, por lo general, incluidas provisiones que demuestran la ausencia de acuerdo internacional sobre la propiedad de regular dicha actividad. 
En algunos casos, el derecho deja sin regular la violencia política; en otros, el derecho es ambivalente, proporcionando una base para argumentos conflictivos. $Y$ lo peor, es que el Derecho tiene importantes vías para legitimar el temor internacional y proteger a los terroristas del castigo como criminales.

Esas definiciones no son producto de negligencia o errores, sino que son intencionales. Esta aseveración constituye mi primera tesis, como intentaré demostrarla en seguida.

Dicha intencionalidad que incrementa la confusión conceptual y, por tanto, la falta de acuerdo, está dada por el inîerés de algunos Estados en preservar la vigencia y la legitimidad de las acciones de los Ilamados "Frentes Nacionales de Liberación Nacional", generalmente de inspiración marxista.

En tal sentido, diversas Secretarías Generales de las Naciones Unidas, han tropezado con este interés cuando han incluido en la Agenda de la Asamblea General la definición y condena del terrorismo.

La primera iniciativa la adoptó Kurt Waldheim, el 8 de septiembre de 1972, después de dos ataques terroristas: Violentistas japoneses, el 30 de marzo del mismo año, junto a miembros de la OLP mataron a 28 pasajeros civiles e hirieron a 78 en el Aeropuerto Lod de Israel y, cuando miembros de la Organización de Septiembre Negro mataron a 11 integrantes de la delegación Olímpica Israelí en Munich.

La proposición de Waldheim provocó gran oposición que adoptó la forma de protestar que se condenaba el terrorismo sin considerar sus causas. El Secretario General, reiteró su petición el 20 de septiembre, pero accedió por presión a añadir "que no era bueno considerar terrorismo sin tomar en cuenta al mismo tiempo, las situaciones subyacentes que incrementan el terrorismo y la violencia en muchas partes del mundo", asegurando que no intentaba "afectar principios aprobados por la Asamblea General, tales como el colonialismo y los deseos de independencia y liberación de los pueblos".

Las concesiones del Secretario General tuvieron gran trascendencia:

Atribuyendo actos de terrorismo a la injusticia y a la frustración, obviamente se les excusa si es que no se les justifica.

Los conceptos de "independencia" y de "liberación" adoptados como principios en otras Asambleas Generales, apoyan el de “autodeterminación", y a las guerras nacionales de liberación, para cuyo propósito los pueblos oprimidos estaban autorizados para usar cualquier medio válido, incluyendo los armados.

Durante la discusión, el representante cubano rechazó cualquier propuesta de "reglas para el propósito de señalar límites legales a la revolución armada".

El representante de Madagascar, expresó:

"Actos de terrorismo basados en venganzas personales deben ser condenados. Actos de Política Terrorista usados para reivindicar derechos reconocidos por las Naciones Unidas son legítimos". 
Estas afirmaciones han sido repetidas en la Asamblea General en una u otra forma, en los años siguientes al primer debate, aprobando 7 resoluciones hasta 1985. Las más importantes son las de 1977, la cual invita a estudiar primero las causas y después los actos y las recomendaciones.

La de 1979, por primera vez condena el terrorismo pero, referida al Protocolo de la Convención de Ginebra, la cual buscaba otorgarle a los grupos combatientes de guerras de liberación nacional la protección de las leyes de guerra. Y la de 1985, después de una serie de actos terroristas, la Asamblea General acordó una resolución que "inequívocamente condena como criminal, todo acto, método y prácticas de terrorismo". Además, llama a la cooperación internacional en contra de él. Al mismo tiempo, sin embargo, reafirma el derecho inalienable de cada pueblo para su autodeterminación y la legitimidad de luchar contra regímenes coloniales, racistas y otras formas de dominación alienante.

Esta Resolución ha tenido directas y graves consecuencias sobre la acción de la Justicia.

El punto central que obstaculiza o paraliza la acción de la justicia en el caso de las extradiciones, es el carácter de acción política, que atribuyen a los actos terroristas. A pesar que la mayoría de los países tienen tratados de extradición, ésta es frecuentemente rechazada, basada en ese argumento.

El problema se agrava, toda vez que los países más afectados por el terrorismo $y$, por tanto, más interesados en combatirlos, v.gr.: USA, también reconocen que pueblos oprimidos están algunas veces justificados para el uso de la fuerza siempre y cuando, dicho uso sea apropiado; por ejemplo: respetar las leyes de la guerra y las acciones no deben estar dirigidas a civiles inocentes, incluso la toma de rehenes y la tortura. Los casos de la ayuda a los grupos de los "contra" en Nicaragua y a los rebeldes afganos ilustran esta política.

Lo expuesto hasta ahora, permite concluir que las dificultades para definir en base a un consenso internacional amplio el concepto de terrorismo que permita, a su vez, una acción eficaz de los derechos nacional e internacional en el combate del fenómeno, tienen sus bases, principalmente, en el conflicto Este-Oeste, cuyo carácter es esencialmente ideológico.

Como ya se dijera, el terrorismo es una de las dimensiones de la violencia política, principalmente de grupos minoritarios que pretenden transformar radicalmente las estructuras sociales de un Estado en términos de acceder al poder político y militar, a fin de incluir a dicho Estado dentro de la esfera de influencia soviética.

Dicha acción se ejecuta mediante la intervención de Estados prosoviéticos que ejercen el rol (según J. Galtung) de imperialismo por delegación; tales son los casos de la injerencia de Cuba en Granada, Nicaragua (y de ésta en El Salvador), Centroamérica, Angola y Yemen del Sur. 
En virtud de lo expuesto, una definición del concepto de terrorismo no puede tener un carácter neutral a la luz de la evidencia de que, en tanto fenómeno, obedece en casi todos los casos, a una concepción utópica, orientada hacia la transformación de las estructuras sociopolíticas y económicas de una sociedad, representando, como método, un arma de carácter psicosociológico de propaganda, utilizada por grupos armados partidarios de la violencia política como medio de conquistar el poder.

A modo de ensayo, proponemos la siguiente definición de terrorismo, desde la perspectiva de la amenaza, que implica el terrorismo para Occidente; definición que excluye el terrorismo de Estado.

Es todo acto premeditado, fruto de una organización vinculada a grupos que practican la violencia política como medio para transformar radicalmente las estructuras de una sociedad, actos basados en la violencia o amenaza de ella, discriminada o no, dirigida contra las personas, las instituciones o la propiedad, a fin de producir temor en la población y disminuir la confianza en las autoridades respecto de su rol de garantizar los derechos básicos de las personas. Dos atributos principales lo caracterizan: por una parte, actúa como elemento propagandístico y, por otra, es una organización que puede estar dirigida por un Estado, respaldado por un país o no apoyado por ninguno, es decir, que no recibe apoyo sustancial de ningún gobierno y cuyas acciones son autónomas.

Esta última condición es residual, ya que el número de grupos terroristas que no gozan de alguna forma de asistencia gubernamental, está bajando rápidamente.

En América del Sur, el caso más claro parece ser el de Sendero Luminoso, al cual, hasta el momento, no se le ha podido demostrar vínculos con algún Estado promotor. En cambio, surge el fenómeno del narcoterrorismo en Perú y Colombia, bajo la forma de una cooperación y apoyo recíprocos entre los grupos armados insurgentes que utilizan como una de sus armas el terrorismo y los procesadores $y$ narcotraficantes con los cuales comparten zonas "liberadas".

Sin embargo, la vinculación con un Estado es el elemento fundamental de identificación. Los planificadores defensivos (antiterroristas) deben conocer la afiliación con el Estado para prever los probables objetivos del terrorista y el nivel de sofisticación tecnológica del enemigo.

Como último elemento de análisis, cabe preguntarse ahora por la relación entre terrorismo y violencia armada, por una parte, y la inestabilidad política y la interrupción del estado de derecho por otra.

Hemos postulado que el terrorismo es una de las armas que utilizan los grupos insurgentes que practican la violencia política y la lucha de clases para alcanzar sus propósitos político-ideológicos.

Un análisis empírico de la correlación entre violencia armada-terrorismo y la inestabilidad política en los 11 países más inestables de América Latina, correlación 
calculada con el coeficiente de Pearson, arrojó un valor de $+0,64$, que es estadísticamente significativo para un alfa de $95 \%$.

Dicha correlación amerita cierta explicación: ese valor es uno de los resultados de la Tesis de Magister en Estudios Internacionales que este autor realizará sobre el tema “Estabilidad Política en América Latina y el Caribe Anglófono: Un Estudio Comparado"; la presencia de tal correlación está basada en la medición de la variable violencia política-terrorismo, durante la década del sesenta, operacionalizada por Duff y McCamant, sobre la base del número de días informados de oposición armada al Gobierno; por el número de muertos y heridos por cada 10 millones de habitantes y por el número de participantes en acciones violentistas por cada un millón de personas.

Por otra parte, la inestabilidad política fue calculada para el período 1970-1983, ya que se encontró que la violencia armada junto al terrorismo predecirian la inestabilidad en el plazo de 10 años, como promedio. Este hallazgo constituye mi segunda tesis $y$, quizás, la de más valor.

La inestabilidad fue medida mediante el cálculo del cuociente entre la diferencia del número de gobiernos observados y el número de gobiernos constitucionalmente esperados (como divisor) y el número de gobiernos esperados (como dividendo).

El índice posee un valor de cero cuando el número de gobiernos observados es igual al de gobiernos esperados, es decir, diferencia igual a cero. El índice mide el porcentaje de gobiernos que excede al número constitucionalmente esperable. Refleja las interrupciones del proceso normal constitucional de sucesión del poder ejecutivo.

El fundamento de la hipótesis que subyace a la relación postulada entre violencia armada-terrorismo e inestabilidad política, es la siguiente:

Sostiene que dados ciertos niveles de violencia armada, la continuidad de la transferencia constitucionalmente pautada del gobierno es interferida por la intervención militar, como reacción a dicho proceso colapsante para la sociedad, con el propósito de combatir eficazmente a los grupos armados opositores, a fin de restaurar el estado de cosas previas a la desintegración social, política y económica del país.

El valor de la correlación encontrada revela la plausibilidad de la hipótesis, avalada por la experiencia histórica de ese conjunto de 11 países que vieron interrumpidos sus procesos constitucionales de sucesión de gobiernos por intervención de las fuerzas armadas, frente a un aumento sostenido de la violencia política armada y el terrorismo en la década anterior.

La intervención de las fuerzas militares regulares, a fin de combatir eficazmente la violencia política armada y el terrorismo, necesariamente deben interrumpir por un tiempo que es variable el estado de derecho hasta ese momento vigente $y$ 
actuar en forma sumaria $y$, muchas veces, utilizando métodos similares a la de los grupos insurgentes, a fin de poder combatir en igualdad de condiciones.

\section{CONCLUSIONES Y SUGERENCIAS}

1. El terrorismo practicado en América Latina está inspirado en el propósito de transformar sustancialmente las estructuras de las sociedades donde actúan, orientándose hacia la implantación de regímenes socialistas, aunque en un comienzo, la acción se dirige a derrocar gobiernos dictatoriales, como son los casos de Cuba y Nicaragua. La excepción la constituye el caso de los "contra", orientados a revertir la transformación socialista.

2. El terrorismo, salvo el caso de Sendero Luminoso, en Peru, es el brazo propangandístico de grupos armados que practican la violencia política armada y la lucha de clases.

3. El terrorismo y la violencia política armada, dados ciertos niveles, predice la intervención de las FF.AA. del país afectado en un lapso aproximado de 10 años, produciendo inestabilidad política y la interrupcion temporal del estado de derecho.

4. El terrorismo, salvo poquísimas excepciones, posee apoyo más o menos directo de Estados extranjeros, mediante el mecanismo del imperialismo delegado; así, en América Latina actúan Cuba y Nicaragua.

5. Los obstáculos para una eficaz acción del derecho internacional y nacional para combatirlo han sido creados intencionalmente en el seno de la Asamblea General de las N.U., para proteger al terrorista mediante la defensa argumentativa de "acción política".

6. Los grupos terroristas que carecen de vínculos con Estados, han dado origen al fenómeno del narcoterrorismo, particularmente en Perú y Colombia, no obstante que el terrorismo y los grupos insurgentes colombianos reciben apoyo extranjero.

7. A modo de sugerencia, proponemos analizar la moción consistente en recomendar a los Gobiernos de los Estados la creación y desarrollo de fuerzas policiales y/o militares especializadas en la lucha antiterrorista, actuando coordinadamente entre sí mediante convenios entre los Estados. 